Examining the antecedents of Facebook acceptance via structural equation modeling: A case of CEGEP students

Tenzin Doleck

Paul Bazelais

David John Lemay

McGill University, Montreal, QC, Canada

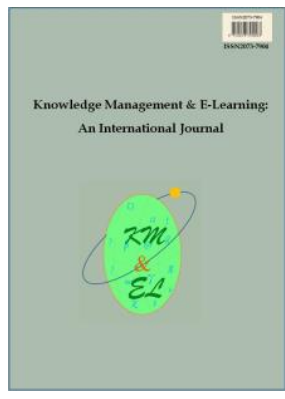

Knowledge Management \& E-Learning: An International Journal (KM\&EL) ISSN 2073-7904

Recommended citation:

Doleck, T., Bazelais, P., \& Lemay, D. J. (2017). Examining the antecedents of Facebook acceptance via structural equation modeling: A case of CEGEP students. Knowledge Management \& E-Learning, 9(1), 69-89. 


\title{
Examining the antecedents of Facebook acceptance via structural equation modeling: A case of CEGEP students
}

\section{Tenzin Doleck*}

McGill University, Montreal, QC, Canada

E-mail: tenzin.doleck@mail.mcgill.ca

\section{Paul Bazelais}

McGill University, Montreal, QC, Canada

E-mail: paul.bazelais@mail.mcgill.ca

\section{David John Lemay}

McGill University, Montreal, QC, Canada

E-mail: david.lemay@mail.mcgill.ca

*Corresponding author

\begin{abstract}
Although the last decade has witnessed social networking sites of varied flavors, Facebook's user growth continues to balloon, and relatedly, Facebook remains popular among the college populace. While there has been a growing body of work on ascertaining antecedents of Facebook use among college students, Collège d'enseignement général et professionnel (CEGEP) students' acceptance of Facebook remains underexplored. The purpose of this study was to analyze CEGEP students' acceptance of Facebook using the technology acceptance model (TAM). Structural equation modeling was conducted on data from a survey of 214 CEGEP students. We find that Facebook use is motivated by the core TAM constructs as well as the added factors of peer influence, perceived enjoyment, perceived self-efficacy, relative advantage, risk, and trust.
\end{abstract}

Keywords: Technology acceptance; Facebook; CEGEP; Antecedents of technology use; Social media; College students

Biographical notes: Tenzin Doleck is a doctoral student at McGill University in Montreal, QC.

Paul Bazelais is a doctoral student at McGill University and an instructor at John Abbott College in Montreal, QC.

David John Lemay is a doctoral candidate at McGill University in Montreal, QC. 


\section{Introduction}

Facebook is the world's largest social networking site, with over 1.4 billion users to date (Newsroom, 2016). The way social media changes our interactions with others continues to be the subject of much debate. Turkle (2011) argued that social networks instrumentalize relationships and provide the illusion of connection yet all at once distances ourselves from each other. For instance, a Facebook friend is only superficially related to being a friend in real life. It gives the appearance of connectedness without having to engage in the hard work required for maintaining a friendship in real life.

Given the widespread adoption of social networking technology and owing to the concerns of social commentators including Turkle and others about their effects, it is important to understand why people choose to use social networks such as Facebook. To better understand how technology shapes social interactions, it appears necessary to first understand the antecedents of social network technology acceptance and use. Understanding the underlying motivations for acceptance of Facebook is key to leverage the potential of platforms such as Facebook for educational uses (Lampe, Wohn, Vtak, Ellison, \& Wash, 2011; Doleck, Bazelais, \& Lemay, 2016). Moreover, a better understanding of the factors of technology acceptance can help inform the design of software applications by informing on the uses to which individuals apply such technologies. Thus, the purpose of our study is to examine and understand the antecedents of Facebook acceptance among students enrolled at an English-language CEGEP located in Montreal, Canada.

\section{Literature review}

Technology acceptance is an important area of research in information systems (Legris, Ingham, \& Collerette, 2003; Venkatesh, \& Davis, 2000). A number of models have been widely applied to understand users' behavioral intentions towards use of technology, such as: Theory of Reasoned Action (TRA; Fishbein \& Ajzen, 1975), Technology Acceptance Model (TAM; Davis, 1989), Theory of Planned Behavior (TPB; Ajzen, 1991), Model of PC Utilization (Thompson, Higgins, \& Howell, 1991), Innovation Diffusion Theory (Rogers, 2003), and Unified Theory of Acceptance and Use of Technology (UTAUT; Venkatesh, Morris, Davis, \& Davis, 2003). The present study relies on the welldocumented technology acceptance model (Davis, 1989; Davis, Bagozzi, \& Warshaw, 1989), which postulates that acceptance and usage of technology are affected by users' attitudes and beliefs. In this section, we first describe the TAM model, and subsequently build and present our hypothesized model.

\subsection{TAM model: Core constructs}

The TAM, developed by Davis (1989), has been employed in various fields to investigate a plethora of technology-acceptance related questions. It is one of the most widely cited models in information systems research. As illustrated in the common operationalization of TAM in Fig. 1, the TAM posits that users' behavioral intentions predict actual use (Davis et al., 1989). Thus, investigations are geared toward unearthing constructs which could act as determinants of intentions.

An immediate determinant of intentions is users' attitudes toward technology use, which in turn are influenced by the users' beliefs (subjective appraisal of the technology). The two personal beliefs in the TAM that exert influence on attitudes towards use include: perceived ease of use and perceived usefulness. Perceived ease of use is defined as "the 
degree to which a person believes that using a particular system would be free of effort" (Davis et al., 1989, p. 320). In contrast, perceived usefulness is defined as "the degree to which a person believes that using a particular system would enhance his or her job performance" (Davis, 1989, p. 320). As the model (Fig. 1) demonstrates, perceived usefulness is directly related to behavioral intention, and perceived ease of use affects behavioral intention indirectly through perceived usefulness and attitude (Davis, 1989).

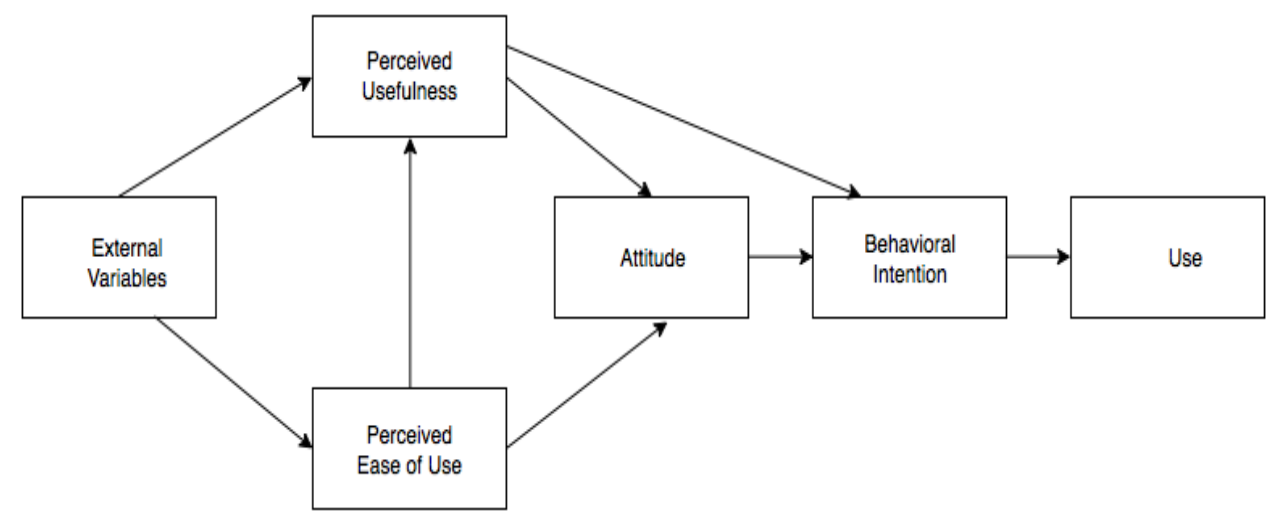

Fig. 1. Technology acceptance model. Adapted from Davis et al. (1989)

\subsection{Moderating factors}

Schepers and Wetzel (2007) found moderating effects for type of respondent, type of technology, and cultural setting. In their meta-analysis, they found significant effects for respondent type, technology type, and cultural setting. Students showed stronger effects for 12 of 15 pairwise comparisons than non-students. Microcomputer adoption studies showed lower effects in general. These findings are in alignment with Gefen, Karahanna, and Straub (2003) who found that consumer habits account for up to $40 \%$ of variance in intentions to use. As Schepers and Wetzel (2007) write, "[i]n these cases, repeated previous behavior dictates current behavior independently of rational assessments (Triandis, 1971)" (p. 100). They also found that cultural setting affected 7 of 15 relationships by comparing Western and non-Western studies, however, not in the direction that one would expect given that in collective societies, subjective norm would be expected to have a stronger influence on intentions to use but that does not appear to be the case. The authors interpret this as supporting findings by Straub, Keil, and Brenner (1997) and McCoy, Everard, and Jones (2005) that TAM might be specific to Western societies.

\subsection{TAM model: Original formulations of the TAM}

While the original TAM has been empirically tested and validated in a number of studies and contexts (Venkatesh \& Davis, 2000), researchers have pushed for a need to include additional variables in the original TAM (Venkatesh \& Davis, 1996). In studies extending the TAM, researchers have included a number of domain-specific constructs to fit their research context. For the present study, we employ an extended TAM incorporating six plausible constructs drawn from the literature on technology acceptance representing antecedents to the TAM, namely: trust, risk, peer influence, relative advantage, perceived self-efficacy, and perceived enjoyment. Since the study aimed to identify factors that influence acceptance and use of Facebook by CEGEP students, we chose these added 
constructs as they appeared salient to understanding social network use among a youthful college-age population.

The constructs in the original TAM include: perceived usefulness, perceived ease of use, attitude toward use, behavioral intentions, and use. Based on prior research, the causal linkage flows of the conventional relationships of the TAM are formulated as follows:

H1: Perceived usefulness is positively related to behavioral intention

H2: Perceived usefulness is positively related to attitude toward use

H3: Perceived ease of use is positively related to attitude toward use

H4: Perceived ease of use is positively related to perceived usefulness

H5: Attitude toward use is positively related to behavioral intention

H6: Behavioral Intention is positively related to use

Along with the baseline formulations, our expanded TAM included the causal linkage flows of the additional constructs, trust, risk, peer influence, relative advantage, perceived self-efficacy, and perceived enjoyment, which are formulated below. In the section that follows, we turn our attention to the extended constructs and the relationship formulations.

\section{TAM model: Extended constructs and relationship formulations}

In this section, we introduce the additional salient constructs considered for inclusion in our proposed research model. Additionally, we also enumerate the hypotheses constructed based on the previous studies.

\subsection{Peer influence}

Subjective norm, a social influence variable, is defined as "the perceived social pressure to perform or not to perform the behavior" (Ajzen, 1991, p. 188) and has been shown to affect user commitment toward technology use. Subjective norms reflect how users are influenced by others' perceptions. Venkatesh and Davis (2000) propose the inclusion of subjective norm in an extension to the technology acceptance model (TAM2). Peer influence, a specific form of subjective norm, has been studied in the social and behavioral psychology domain (MacCallum, 2011; Ryan, 2000), and, according to Taylor and Todd (1995), peer influence is considered to be a determinant in technology acceptance. Moreover, others have also acknowledged the importance of social norms on perceived usefulness (Yi, Jackson, Park, \& Probst, 2006). Schepers and Wetzels (2007), who conducted a meta-analysis of the technology acceptance model, investigated the subjective norm antecedent and moderation effects of respondent type, technology type, and cultural setting. In their analysis, a total of 51 articles reporting on a total of 63 studies met the criteria and were included. Their analysis largely confirmed the TAM2 model but also discovered two additional relationships: (1) perceived ease of use $\rightarrow$ behavioral intention and (2) subjective norm $\rightarrow$ attitude towards use.

Social norms are broader and usually cover the influence of schools, professors, higher authority, and other aspects of the social context. Since Facebook is a medium where you are generally dealing with your peers, we decided to focus on peer influence 
instead. In today's age, peers exert an important influence on adolescents (Neufeld \& Maté, 2006). Peer opinion could influence users to conform to the behaviors or suggestions of their friends, thus increasing the perceived usefulness of technology through a kind of virtuous cycle or feedback loop. This leads to the hypothesis:

H7: Peer influence is positively related to perceived usefulness

\subsection{Relative advantage}

Rogers (2003) defined relative advantage as the "degree to which an innovation is perceived as being better than the idea it superseded" (p. 212). While the constructs of relative advantage and perceived usefulness have been used interchangeably in the literature (Venkatesh et al., 2003), others consider the two constructs to be conceptually different. For example, Lok (2015) presents the differences between the two constructs as: "relative advantage is in relative sense whereas perceived usefulness is in absolute sense" (p. 406). Further, Lok (2015) suggests that if users do not see the relative advantage of a technology, they are less likely to assess it as useful. Thus, if a user perceives a relative advantage in using one technology over another, then he/she will likely perceive its usefulness. This leads to the hypothesis:

H8: Relative advantage is positively related to perceived usefulness

\subsection{Perceived self-efficacy}

Users' confidence in their ability to efficiently make use of a technology can affect acceptance behaviors. Bandura's (1995) concept of self-efficacy beliefs has been invoked to provide a potential explanation for this relationship. According to Bandura (1995), perceived self-efficacy "refers to beliefs in one's capabilities to organize and execute the courses of action required to manage prospective situations" (p. 2). Over the years, selfefficacy has been operationalized at situation or context specific levels (Agarwal, Sambamurthy, \& Stair, 2000). For example, computer self-efficacy, a context-specific form of self-efficacy, has been defined as the belief of user's capability to use computers in completing a task (Compeau \& Higgins, 1995). Research examining computer selfefficacy in the context of technology use has documented the positive influence of selfefficacy on perceived ease of use (Agarwal et al., 2000; McFarland \& Hamilton, 2006; Venkatesh, 2000). This leads to the hypothesis:

H9: Self-efficacy is positively related to perceived ease of use

\subsection{Perceived enjoyment}

Venkatesh (2000) defines perceived enjoyment as "the extent to which the activity of using a specific system is perceived to be enjoyable in its own right, aside from any performance consequences resulting from system use" (p. 351). The literature on technology use and adoption has considered perceived enjoyment as a type of intrinsic motivation (Davis, Bagozzi, \& Warshaw, 1992; Teo, Lim, \& Lai, 1999; Venkatesh, 2000). Research examining determinants of perceived ease of use has shown that perceived enjoyment exerts a positive influence on perceived ease of use (Venkatesh, 2000). This leads to the hypothesis:

H10: Perceived enjoyment is positively related to perceived ease of use 


\subsection{Risk and trust}

Risk and trust, two interrelated variables (Mayer, Davis, \& Schoorman, 1995), are salient beliefs involved in relationships and/or transactions. Risk and trust have been shown to be influencing constructs in technology use in the information systems literature (Gefen et al., 2003; Pavlou, 2003), particularly in the domains of e-commerce and online banking. However, these constructs have received scarce coverage in the computermediated communications literature. Since online social networks are built around online behaviors and information transactions, the notion of risk and trust are likely to be influencing factors in the use of a social network such as Facebook. Hence, research is needed on the nature and specific influence of risk and trust on social network use.

Appropriating the tested roles of risk and trust from the information systems literature, we propose the following links between these two variables and our expanded TAM. In online transactions, users' lack of trust can be an obstacle to both adoption and acceptance of technology (Pavlou, 2003; Yousafzai, Foxall, \& Pallister, 2010). Although numerous definitions of trust exist, for the purposes of this paper, trust is viewed in terms of transactions in a social network and the social network as a transacting entity. Trust has been shown to positively impact attitudes (Jarvenpaa, Tractinsky, \& Vitale, 2000). Trust has also been shown to reduce risk beliefs about transactions with entities (Pavlou, 2003; Yousafzai et al., 2010). Thus, trust and risk appear to be inversely related. Further, trust positively influences behavioral intentions since it reduces uncertainty (Pavlou, 2003). This leads to the hypotheses:

\section{H11: Trust is positively related to attitudes}

\section{H12: Trust is negatively related to risk}

\section{H13: Trust is positively related to behavioral intentions}

Being online inherently poses a level of uncertainty and risk for users (Pavlou, 2003; Yousafzai et al., 2010), as actions can have unanticipated consequences. Users' willingness to engage in the use of technology is negatively impacted by risk perceptions since perceived risk has been shown to negatively impact behavioral intentions (Pavlou, 2003). Indeed, the theory of reasoned action (Fishbein \& Ajzen, 1975) posits that a users' willingness is affected by his/her risk perceptions. This leads to the hypothesis:

H14: Risk is negatively related to behavioral intention

\subsection{Research model}

Based on the above discussion accounting for the additional constructs and relationship formulations, we conceptualize and present the following augmented research model (Fig. 2) to explicate students' Facebook usage. 


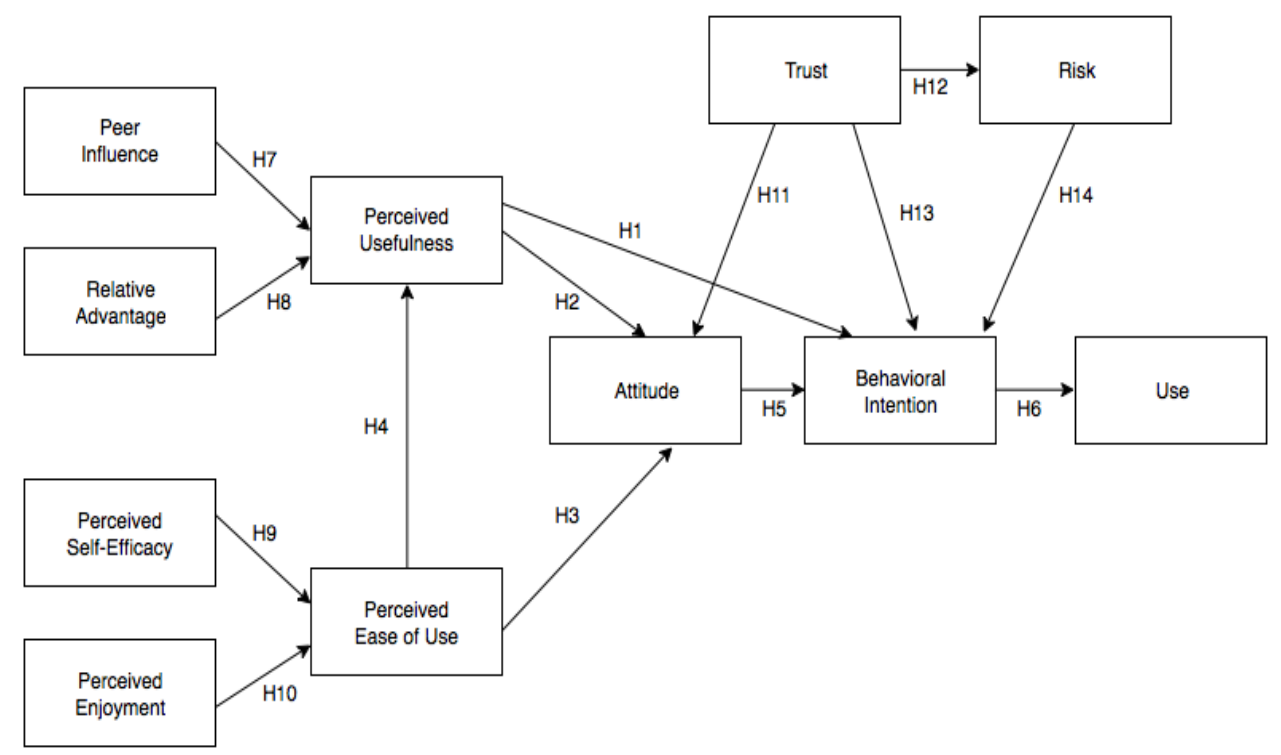

Fig. 2. Proposed model

\section{Methodology}

Survey measures were adapted to the context of Facebook to test our proposed model. The multiple-item questionnaire on Facebook use was administered to students at an English-language CEGEP in Montreal, Quebec.

\subsection{Instruments}

For this study, existing scales (Davis et al., 1989; Gefen, 2002; Lai \& Chen, 2011; Moore \& Benbasat, 1991; Taylor \& Todd, 1995) were adapted to fit the study context and purpose. The questionnaire consisted of 40 items to measure the 11 constructs in the proposed research model. The constructs were measured on a 7-point Likert scale (from 1 $=$ strongly disagree to $7=$ strongly agree $)$ because it is considered a more accurate measure of a participant's true evaluation (Jamieson, 2004; Finstad, 2010).

\subsection{Data collection and participant profile}

Participants were volunteers drawn from class sections at an English-language CEGEP in Montreal, Quebec. A total of 214 usable responses (after removal of invalid responses such as responses with multiple selections for a single item) were included in the final analysis. Of the 214 participants, 100 were female and 114 were male; thus, gender was relatively evenly distributed. The average age of participants was 18.173 (SD: 1.354).

\section{Data analysis and findings}

Structural equation modeling was employed to construct and test our proposed model. Several factors affect sample size requirements in conducting structural equation modeling. The sample size in this study meets the general guidelines suggested in the 
PLS-SEM literature: "(1) ten times the largest number of formative indicators used to measure one construct or (2) ten times the largest number of structural paths directed at a particular latent construct in the structural model" (Hair, Ringle, \& Sarstedt, 2011, p. 144). The present study used a partial least squares (PLS) path modeling approach to build the structural model and test the proposed hypotheses. PLS modeling (Wold, 1982) is a second-generation statistical technique that belongs to the class of variance-based structural equation modeling. PLS is suitable for analyses that have small sample size and less stringent assumption requirements (Chin, 1998; Hulland, 1999). In this study, the SmartPLS software (Ringle, Wende, \& Becker, 2015) was used for generating and evaluating the measurement and, subsequently, the structural model. Our analysis follows the general two-step approach to PLS-SEM: a test of the measurement model and then an estimation of the structural part of the SEM (Hair et al., 2011).

\subsection{Measurement model}

The first step of the analysis involved assessing the measurement model by means of factor analysis using the PLS algorithm. Measurement model assessment is required to evaluate the psychometric properties, i.e., consistency and validity of the variables. The adequacy of the measurement model was assessed using factor loadings, internal consistency reliability, convergent validity, and discriminant validity statistics. In Table 1 , the endogenous and exogenous constructs are abbreviated to ease readability.

Table 1

Endogenous and exogenous constructs

\begin{tabular}{llll}
\hline Endogenous constructs & Abbreviation & Exogenous constructs & Abbreviation \\
\hline Perceived Usefulness & PUS & Trust & TRU \\
Perceived Ease of Use & PEU & Peer Influence & PIN \\
Attitude & ATT & Relative Advantage & RAD \\
Risk & RIS & Perceived Self-Efficacy & PSE \\
Behavioural Intention & BIN & Perceived Enjoyment & PEN \\
Use & USE & & \\
\hline
\end{tabular}

The reliabilities for items are measured via the factor loadings. It is generally recommended that the factor loadings should exceed the threshold value of 0.70 (Chin, 1998); however, others consider a cut-off value of 0.50 to be sufficient (Hulland, 1999). As presented in Table 2, all loadings were greater than 0.50 , with majority of loadings exceeding 0.70 . Thus, reliabilities for all items were assured. To verify the reliability of the constructs, composite and Cronbach's alpha are conventionally reported. However, composite reliability is generally considered a better measure of internal consistency (Fornell \& Laker, 1981; Teo \& Fan, 2013). The composite reliabilities of the different measures ranged from 0.796 to 0.958 (Table 2). All composite reliability values exceeded the recommended threshold value of 0.70 (Gefen, Straub, \& Boudreau, 2000), suggesting adequate composite reliabilities. Convergent validity was assessed through the Average Variance Extracted (AVE) test on the variables. The average variance extracted of the different measures ranged from 0.505 to 0.885 (Table 2); these values are greater than the recommended threshold value of 0.50 (Fornell \& Laker, 1981). 
Table 2

Factor loadings, internal consistency reliability, \& convergent validity

\begin{tabular}{|c|c|c|c|c|}
\hline Construct & Items & Loading & Composite Reliability & AVE \\
\hline \multirow[t]{6}{*}{ Perceived Usefulness } & PUS1 & 0.717 & 0.857 & 0.505 \\
\hline & PUS2 & 0.700 & & \\
\hline & PUS3 & 0.544 & & \\
\hline & PUS4 & 0.776 & & \\
\hline & PUS5 & 0.653 & & \\
\hline & PUS6 & 0.836 & & \\
\hline \multirow[t]{5}{*}{ Perceived Ease of Use } & PEU1 & 0.853 & 0.918 & 0.690 \\
\hline & PEU2 & 0.871 & & \\
\hline & PEU3 & 0.853 & & \\
\hline & PEU4 & 0.783 & & \\
\hline & PEU5 & 0.790 & & \\
\hline \multirow[t]{5}{*}{ Attitude } & ATT1 & 0.769 & 0.888 & 0.614 \\
\hline & ATT2 & 0.776 & & \\
\hline & ATT3 & 0.783 & & \\
\hline & ATT4 & 0.742 & & \\
\hline & ATT5 & 0.845 & & \\
\hline \multirow[t]{4}{*}{ Trust } & TRU1 & 0.784 & 0.939 & 0.794 \\
\hline & TRU2 & 0.923 & & \\
\hline & TRU3 & 0.931 & & \\
\hline & TRU4 & 0.917 & & \\
\hline \multirow[t]{4}{*}{ Risk } & RIS1 & 0.836 & 0.923 & 0.749 \\
\hline & RIS2 & 0.861 & & \\
\hline & RIS3 & 0.874 & & \\
\hline & RIS4 & 0.889 & & \\
\hline \multirow[t]{3}{*}{ Peer Influence } & PIN1 & 0.830 & 0.796 & 0.567 \\
\hline & PIN2 & 0.703 & & \\
\hline & PIN3 & 0.721 & & \\
\hline \multirow[t]{3}{*}{ Relative Advantage } & RAD1 & 0.877 & 0.873 & 0.696 \\
\hline & RAD2 & 0.805 & & \\
\hline & RAD3 & 0.819 & & \\
\hline \multirow[t]{3}{*}{ Perceived Self-Efficacy } & PSE1 & 0.935 & 0.950 & 0.863 \\
\hline & PSE1 & 0.959 & & \\
\hline & PSE1 & 0.892 & & \\
\hline \multirow[t]{3}{*}{ Perceived Enjoyment } & PEN1 & 0.946 & 0.958 & 0.885 \\
\hline & PEN1 & 0.948 & & \\
\hline & PEN1 & 0.928 & & \\
\hline \multirow[t]{2}{*}{ Behavioural Intention } & BIN1 & 0.947 & 0.934 & 0.875 \\
\hline & BIN1 & 0.924 & & \\
\hline \multirow[t]{2}{*}{ Use } & USE1 & 0.908 & 0.910 & 0.834 \\
\hline & USE1 & 0.918 & & \\
\hline
\end{tabular}


To assess discriminant validity, traditionally two approaches have been used: The Fornell-Larcker criterion (Fornell \& Larcker, 1981) and cross-loadings. Following the Fornell-Larcker criterion, the square roots of the AVEs for two latent variables must each be greater than the correlations between those two variables (Fornell \& Larcker 1981). In Table 3, the square roots of the AVEs are highlighted in bold along the diagonal. It can be observed that the Fornell-Larcker criterion is met by applying the methodology suggested by Fornell \& Larcker (1981), i.e., all the diagonal values are greater than the off-diagonal numbers in the corresponding rows and columns. Thus, the data present adequate discriminant validity. Recently, Henseler, Ringle, and Sarstedt (2015) proposed an alternate approach, the heterotrait-monotrait ratio of correlations (HTMT) as an alternative to assess discriminant validity. We supplement the previous discriminant validity assessment using the HTMT criterion. According to Henseler et al. (2015), if the HTMT value is below 0.90 for two constructs and the HTMT confidence intervals does not contain 1 then discriminant validity is established. In Table 4, all HTMT values are below the 0.90 cut-off value, and in Table 5 none of the intervals contains 1 , thus ensuring discriminant validity.

Table 3

Discriminant validity check

\begin{tabular}{|c|c|c|c|c|c|c|c|c|c|c|c|}
\hline & ATT & BIN & PEN & PEU & PIN & PSE & PUS & RAD & RIS & TRU & USE \\
\hline ATT & 0.784 & & & & & & & & & & \\
\hline BIN & 0.640 & 0.935 & & & & & & & & & \\
\hline PEN & 0.677 & 0.647 & 0.941 & & & & & & & & \\
\hline PEU & 0.432 & 0.336 & 0.380 & 0.831 & & & & & & & \\
\hline PIN & 0.423 & 0.458 & 0.375 & 0.256 & 0.753 & & & & & & \\
\hline PSE & 0.300 & 0.271 & 0.347 & 0.683 & 0.362 & 0.929 & & & & & \\
\hline PUS & 0.709 & 0.551 & 0.563 & 0.320 & 0.428 & 0.206 & 0.711 & & & & \\
\hline RAD & 0.643 & 0.540 & 0.507 & 0.276 & 0.417 & 0.159 & 0.626 & 0.834 & & & \\
\hline RIS & 0.076 & 0.092 & 0.113 & 0.104 & -0.077 & 0.007 & -0.006 & -0.007 & 0.865 & & \\
\hline TRU & 0.500 & 0.430 & 0.410 & 0.417 & 0.279 & 0.325 & 0.332 & 0.244 & 0.438 & 0.891 & \\
\hline USE & 0.510 & 0.421 & 0.334 & 0.216 & 0.402 & 0.303 & 0.371 & 0.300 & 0.006 & 0.270 & 0.913 \\
\hline
\end{tabular}

Table 4

Discriminant validity check- HTMT

\begin{tabular}{|c|c|c|c|c|c|c|c|c|c|c|c|}
\hline & ATT & BIN & PEN & PEU & PIN & PSE & PUS & RAD & RIS & TRU & USE \\
\hline \multicolumn{12}{|l|}{ ATT } \\
\hline BIN & 0.733 & & & & & & & & & & \\
\hline PEU & 0.493 & 0.383 & 0.419 & & & & & & & & \\
\hline PIN & 0.590 & 0.623 & 0.486 & 0.346 & & & & & & & \\
\hline RAD & 0.788 & 0.655 & 0.583 & 0.341 & 0.607 & 0.203 & 0.779 & & & & \\
\hline RIS & 0.131 & 0.106 & 0.128 & 0.119 & 0.111 & 0.047 & 0.082 & 0.072 & & & \\
\hline TRU & 0.561 & 0.484 & 0.445 & 0.465 & 0.364 & 0.357 & 0.386 & 0.288 & 0.482 & & \\
\hline USE & 0.623 & 0.501 & 0.384 & 0.256 & 0.592 & 0.356 & 0.467 & 0.380 & 0.048 & 0.313 & \\
\hline
\end{tabular}


Table 5

Discriminant validity check- HTMT confidence intervals

\begin{tabular}{|c|c|c|c|c|c|c|c|}
\hline & $\begin{array}{l}\text { Original } \\
\text { Sample }\end{array}$ & $2.5 \%$ & $97.5 \%$ & & $\begin{array}{l}\text { Original } \\
\text { Sample }\end{array}$ & $2.5 \%$ & $97.5 \%$ \\
\hline $\mathrm{BIN} \rightarrow \mathrm{ATT}$ & 0.733 & 0.635 & 0.818 & RIS -> ATT & 0.131 & 0.091 & 0.275 \\
\hline $\mathrm{PEN} \rightarrow \mathrm{ATT}$ & 0.746 & 0.648 & 0.827 & RIS $->$ BIN & 0.106 & 0.040 & 0.296 \\
\hline $\mathrm{PEN} \rightarrow \mathrm{BIN}$ & 0.721 & 0.604 & 0.817 & RIS $\rightarrow$ PEN & 0.128 & 0.051 & 0.296 \\
\hline $\mathrm{PEU} \rightarrow \mathrm{ATT}$ & 0.493 & 0.357 & 0.619 & $\mathrm{RIS} \rightarrow \mathrm{PEU}$ & 0.119 & 0.066 & 0.296 \\
\hline $\mathrm{PEU} \rightarrow \mathrm{BIN}$ & 0.383 & 0.256 & 0.504 & RIS $\rightarrow$ PIN & 0.111 & 0.082 & 0.325 \\
\hline PEU $\rightarrow$ PEN & 0.419 & 0.277 & 0.557 & RIS $\rightarrow$ PSE & 0.047 & 0.044 & 0.189 \\
\hline $\mathrm{PIN} \rightarrow \mathrm{ATT}$ & 0.590 & 0.439 & 0.740 & RIS $\rightarrow$ PUS & 0.082 & 0.085 & 0.249 \\
\hline $\mathrm{PIN} \rightarrow \mathrm{BIN}$ & 0.623 & 0.470 & 0.771 & RIS $\rightarrow$ RAD & 0.072 & 0.071 & 0.245 \\
\hline $\mathrm{PIN} \rightarrow \mathrm{PEN}$ & 0.486 & 0.313 & 0.648 & $\mathrm{TRU} \rightarrow \mathrm{ATT}$ & 0.561 & 0.436 & 0.671 \\
\hline $\mathrm{PIN} \rightarrow \mathrm{PEU}$ & 0.346 & 0.230 & 0.525 & $\mathrm{TRU} \rightarrow \mathrm{BIN}$ & 0.484 & 0.352 & 0.597 \\
\hline $\mathrm{PSE} \rightarrow \mathrm{ATT}$ & 0.342 & 0.206 & 0.483 & TRU $\rightarrow$ PEN & 0.445 & 0.304 & 0.568 \\
\hline $\mathrm{PSE} \rightarrow \mathrm{BIN}$ & 0.309 & 0.183 & 0.432 & $\mathrm{TRU} \rightarrow \mathrm{PEU}$ & 0.465 & 0.341 & 0.575 \\
\hline $\mathrm{PSE} \rightarrow \mathrm{PEN}$ & 0.376 & 0.244 & 0.505 & TRU $\rightarrow$ PIN & 0.364 & 0.195 & 0.539 \\
\hline $\mathrm{PSE} \rightarrow \mathrm{PEU}$ & 0.752 & 0.626 & 0.859 & TRU $\rightarrow$ PSE & 0.357 & 0.235 & 0.468 \\
\hline PSE -> PIN & 0.486 & 0.333 & 0.637 & TRU $\rightarrow$ PUS & 0.386 & 0.259 & 0.522 \\
\hline PUS -> ATT & 0.854 & 0.770 & 0.936 & $\mathrm{TRU} \rightarrow \mathrm{RAD}$ & 0.288 & 0.136 & 0.443 \\
\hline PUS -> BIN & 0.648 & 0.521 & 0.764 & TRU $\rightarrow$ RIS & 0.482 & 0.278 & 0.670 \\
\hline PUS -> PEN & 0.638 & 0.519 & 0.743 & $\mathrm{USE} \rightarrow \mathrm{ATT}$ & 0.623 & 0.484 & 0.751 \\
\hline PUS -> PEU & 0.383 & 0.237 & 0.540 & USE $\rightarrow$ BIN & 0.501 & 0.341 & 0.655 \\
\hline PUS -> PIN & 0.601 & 0.449 & 0.769 & USE $\rightarrow$ PEN & 0.384 & 0.223 & 0.535 \\
\hline PUS -> PSE & 0.254 & 0.140 & 0.417 & $\mathrm{USE} \rightarrow \mathrm{PEU}$ & 0.256 & 0.119 & 0.419 \\
\hline RAD $\rightarrow$ ATT & 0.788 & 0.690 & 0.881 & USE $\rightarrow$ PIN & 0.592 & 0.415 & 0.760 \\
\hline RAD -> BIN & 0.655 & 0.536 & 0.759 & USE $\rightarrow$ PSE & 0.356 & 0.221 & 0.488 \\
\hline RAD -> PEN & 0.583 & 0.447 & 0.707 & USE $\rightarrow$ PUS & 0.467 & 0.328 & 0.598 \\
\hline RAD $->$ PEU & 0.341 & 0.178 & 0.516 & USE $\rightarrow$ RAD & 0.380 & 0.213 & 0.544 \\
\hline RAD -> PIN & 0.607 & 0.434 & 0.792 & USE $\rightarrow$ RIS & 0.048 & 0.042 & 0.203 \\
\hline RAD -> PSE & 0.203 & 0.100 & 0.358 & USE $\rightarrow$ TRU & 0.313 & 0.163 & 0.458 \\
\hline RAD -> PUS & 0.779 & 0.669 & 0.888 & & & & \\
\hline
\end{tabular}




\subsection{Structural model}

After checking the individual reliability for each item, and assessing the convergent and discriminant validity of the constructs, the structural model was examined to test the hypotheses by examining the path coefficients and coefficient of determination values. In this study, the structural model was comprised of endogenous constructs (PUS, PEU, ATT, RIS, BIN, \& USE) and exogenous constructs (PIN, RAD, PSE, PEN, and TRU). To assess the structural model, both the PLS algorithm and bootstrapping technique were employed.

The PLS path modeling estimation (generated by the PLS algorithm) is illustrated in Fig. 3, and the bootstrapping results (t-values computed by creating pre-specified samples) are presented in Fig. 4. The properties of the resulting path coefficients $(\beta)$, path significance ( $t$-statistic), and the coefficient of determination $\left(R^{2}\right)$ were used to assess the model. The model was assessed at the 0.05 significance level using two-tailed t-tests. The $R^{2}$ values of endogenous latent variables are assessed using the criterion suggested by (Hair et al., 2011): 0.75 is substantial, 0.50 is moderate, and 0.25 is weak. The structural model was examined to judge whether each of the hypotheses was either supported or rejected.

Predictive relevance was also assessed. Hair et al. (2011) suggest examining Stone-Geisser's $Q^{2}$ values as a criterion of predictive relevance. According to their criteria, $Q^{2}$ values greater than zero indicate that the exogenous constructs have predictive relevance for the endogenous construct. Following the blindfolding procedure, an omission distance was specified as suggested by Hair et al. (2011). All $Q^{2}$ values in Table 6 are greater than zero, indicating that the model had acceptable predictive relevance.

Table 6

Blindfolding results

\begin{tabular}{llll}
\hline Construct & SSO & SSE & $Q^{2}(=1-$ SSE/SSO $)$ \\
\hline ATT & $1,070.000$ & 683.974 & 0.361 \\
BIN & 428.000 & 265.558 & 0.380 \\
PEN & 642.000 & 642.000 & --- \\
PEU & $1,070.000$ & 711.071 & 0.335 \\
PIN & 642.000 & 642.000 & --- \\
PSE & 642.000 & 642.000 & --- \\
PUS & $1,284.000$ & $1,007.897$ & 0.215 \\
RAD & 642.000 & 642.000 & --- \\
RIS & 856.000 & 737.972 & 0.138 \\
TRU & 856.000 & 856.000 & --- \\
USE & 428.000 & 367.050 & 0.142 \\
\hline
\end{tabular}




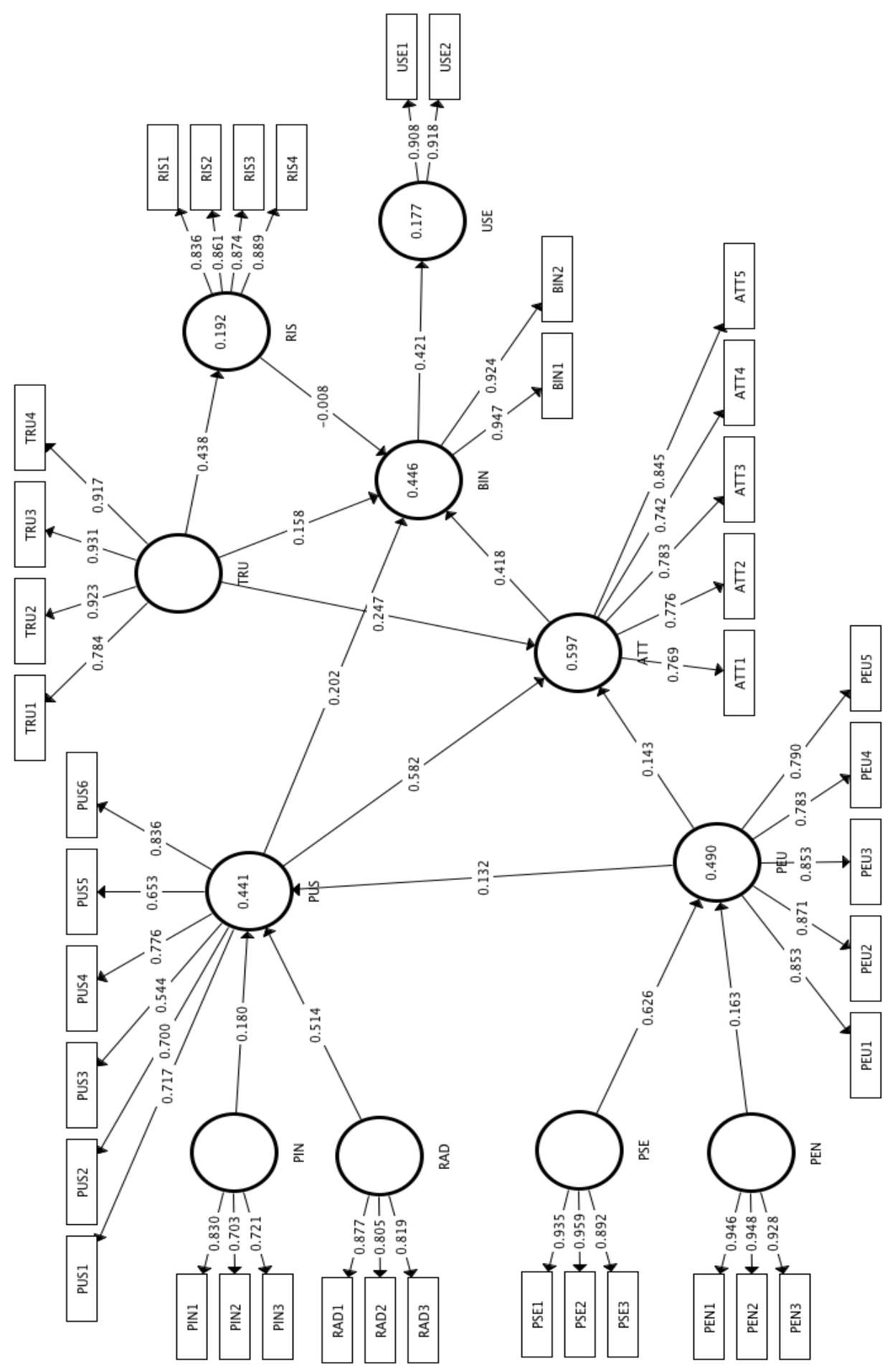

Fig. 3. PLS-SEM results 


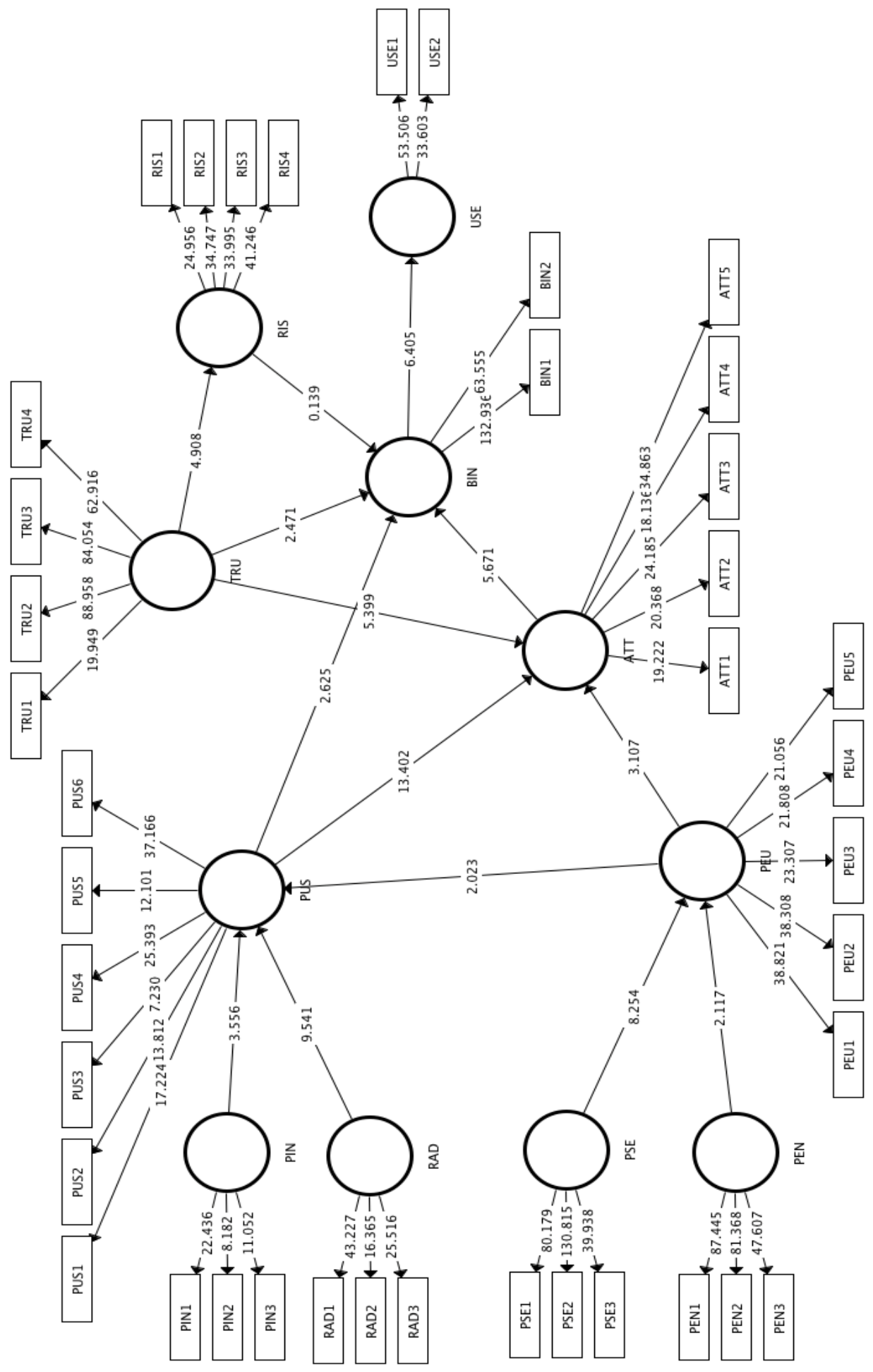

Fig. 4. Bootstrapping results 
From the results, the following observations can be made:

A) Endogenous variable variance

- The $R^{2}$ is 0.177 (weak) for the USE latent variable. The BIN latent variable helped explain $17.7 \%$ of the variance in USE.

- $\quad$ The $R^{2}$ is 0.446 (close to moderate) for the BIN latent variable. The four latent variables (PUS, ATT, TRU, and RIS) explain $44.6 \%$ of the variance in BIN.

- The $R^{2}$ is 0.597 (moderate) for the ATT latent variable. The three latent variables (PUS, PEU, and TRU) explain $59.7 \%$ of the variance in ATT.

- $\quad$ The $R^{2}$ is 0.441 (close to moderate) for the PUS latent variable. The three latent variables (PIN, RAD, and PEU) explain $44.1 \%$ of the variance in PUS.

- $\quad$ The $R^{2}$ is 0.490 (moderate) for the PEU latent variable. The two latent variables (PEN and PSE) explain $49.0 \%$ of the variance in PEU.

- $\quad$ Finally, the $R^{2}$ is 0.192 (weak) for the RIS latent variable. The TRU latent variable helped explain $19.2 \%$ of variance in RIS.

B) Inner model path coefficients

Bootstrapping was used to assess the path coefficients' significance. From Fig. 4, we can check for the significance of the path coefficients of the inner model. Using a two-tailed $t$-test with a significance level of 0.05 , the path coefficient is considered significant if the $t$-statistic exceeds 1.96 (Hair et al., 2011). The results of the hypothesis testing are presented in Table 7.

Table 7

Hypotheses testing

\begin{tabular}{ccccc}
\hline Hypothesis & Path & $\beta$ & $t$-statistic & Result \\
\hline H1 & PUS $\rightarrow$ BIN & 0.202 & $2.625^{* *}$ & Supported \\
H2 & PUS $\rightarrow$ ATT & 0.582 & $13.402^{* *}$ & Supported \\
H3 & PEU $\rightarrow$ ATT & 0.143 & $3.107^{* *}$ & Supported \\
H4 & PEU $\rightarrow$ PUS & 0.132 & $2.023^{*}$ & Supported \\
H5 & ATT $\rightarrow$ BIN & 0.418 & $5.671^{* *}$ & Supported \\
H6 & BIN $\rightarrow$ USE & 0.421 & $6.405^{* *}$ & Supported \\
H7 & PIN $\rightarrow$ PUS & 0.180 & $3.556^{* *}$ & Supported \\
H8 & RAD $\rightarrow$ PUS & 0.514 & $9.541^{* *}$ & Supported \\
H9 & PSE $\rightarrow$ PEU & 0.626 & $8.254^{* *}$ & Supported \\
H10 & PEN $\rightarrow$ PEU & 0.163 & $2.112^{*}$ & Supported \\
H11 & TRU $\rightarrow$ ATT & 0.247 & $5.399^{* *}$ & Supported \\
H12 & TRU $\rightarrow$ RIS & $0.438^{\dagger}$ & $4.908^{* *}$ & Not Supported \\
H13 & TRU $\rightarrow$ BIN & 0.158 & $2.471^{*}$ & Supported \\
H14 & RIS $\rightarrow$ BIN & -0.008 & 0.139 & Not Supported \\
\hline
\end{tabular}

Note. ${ }^{*} p<.05 . * * p<.01 . \dagger$ Direction of path relationship not supported 
Of the 14 hypotheses tested, only two were unsupported (H12 and H14). Overall, the results confirmed the conventional relationships in the original TAM. Specifically, perceived usefulness will have a positive effect on behavioral intention and attitude toward use; perceived ease of use will have a positive effect on attitude toward use and perceived usefulness; attitude toward use will have a positive effect on behavioral intention; and, behavioural intentions will have a positive effect on use.

For the additional linkages tested, two linkages were not supported (TRU $\rightarrow$ RIS and RIS $\rightarrow$ BIN). Contrary to our hypothesized link between TRU and RIS, we found a positive relationship between the two constructs. One possible explanation for this can be made via Luhmann's double contingency theory (Holmström, 2007; Vanderstraeten, 2002), which we elaborate on in the discussion below. Though the relationship between RIS and BIN was found to be negative as hypothesized, there was no statistical support for this link.

\section{Discussion}

Our findings are largely in line with other models which have integrated subjective norm and/or other moderating factors (Burton-Jones \& Hubona, 2006; King \& He, 2006; Sun \& Zhang, 2006; Schepers \& Wetzels, 2007). One problem that is consistently raised is the large variability in correlations and model inclusions (King \& He, 2006). Although the number of moderating variables and the exact relationships are not consistent across each study discussed here, all find support for the effect of moderating variables on the TAM construct.

Findings in this study support Schepers and Wetzels' (2007) meta-analysis results. We found a moderate effect $\left(R^{2}=0.441\right)$ for PUS where the three latent variables (PIN, RAD, and PEU) explained $44.1 \%$ of the variance in PUS. There are conceptual similarities between TAM and IDT, namely perceived usefulness and perceived ease of use in TAM are similar constructs to relative advantage and complexity in IDT (Yi et al., 2006, p.351). Our analysis suggests that RAD and PUS are closely related constructs.

Our findings are in line with King and He's (2006) meta-analysis of 88 empirical studies, which supported the TAM model finding that perceived usefulness mediated perceived ease of use and behavioral intention. According to them, the only context where perceived ease of use has a direct influence was in Internet applications. They also examined moderating effects of type of user and type of usage, concluding that students could be substituted for professionals but not general users, and task and office applications could be considered a single category in TAM research. King and He's (2006) findings on type of user contrast with those of Schepers and Wetzel (2007), however, this could be attributed to the different ways the variables are categorized (in the first, student vs. non-student, and in the second, student, professional, and general user).

Burton-Jones and Hubona (2006) found that external variables could have a direct effect on usage behaviors over and above their mediated effect. However, most TAM research focuses on the core constructs' mediating effects and have not explored whether antecedents such as subjective norm and peer influence have unmediated effect on behavioral intentions (Teo, 2009). Further, McFarland and Hamilton (2006) found that contextual specificity variables such as computer anxiety, prior experience, others' use, organizational support, task structure, system quality, strongly influenced system usage. This is of interest since we did not test for direct effects of our exogenous constructs on usage behaviors and would potentially warrant further study. However, the results show 
the strongest relationships between the core constructs, and furthermore, among those factors which are conceptually related to the core constructs, i.e., RAD $\rightarrow$ PUS, and PSE $\rightarrow$ PEU, which we interpret as the potential evidence for the mediating effect of the PUS and PEU constructs.

Sun and Zhang (2006) summarize their review in a model which largely corresponds with that resulting from Schepers and Wetzel's (2007) meta-analysis. However, they point out that while most of the relationships are statistically significant, they are not entirely consistent between studies. They also reviewed the literature on moderating effects and identified ten moderating factors which they categorize into organizational (voluntariness, task/profession), technological (individual/group, purpose, complexity), and individual factors (intellectual capability, cultural background, gender, age, and experience). Similarly, our model found significant effects for self-efficacy, relative advantage, trust and risk, and subjective norm on perceived ease of use, perceived usefulness, attitude, and behavioral intention. Our results corroborate the direct relationship between perceived usefulness and behavioral intention but also find support for a mediating effect of attitude from perceived ease of use to behavioral intention, which is not included in the meta-analyses discussed above. Unlike these meta-analyses we did not test for direct relationships between subjective norm and attitude, perceived ease of use, or behavioral intention.

\subsection{The counter-intuitive link between trust and perceived risk}

We found a positive relationship between trust and perceived risk contrary to our hypothesizing and contrary to earlier findings by Pavlou (2003) and other studies examining mitigation strategies of perceived information risks among telecommunication services (Libaque-Saenz, Wong, Chang, Ha, \& Park, 2014). We interpret this finding using Luhmann's double contingency theory (Holmström, 2007; Vanderstraeten, 2002 for relevant discussions). In his development of Talcott Parson's problem of double contingency, i.e., how communication is possible between two actors whose understanding is contingent on the recognition of the other, Luhmann examined the way that social systems evolve reflexively in complex and non-linear fashion.

In the context of Facebook, the problem can be formulated as why agents act in ways that appear contrary to their interests even when the anticipated benefits may not outweigh the perceived risks. In Luhmann's analysis, the answer lies in the differential and evolving meaning of risk and trust for the agents involved. In the case of Facebook, the social media company has faced increasing scrutiny of its privacy policy even as people have increasingly moved their social lives online. As Turkle (2011) describes, we have grown accustomed to sharing a great deal of information about ourselves and have become inured to airing our personal lives in public. We don't consider this strange even though a few years ago many would have found the same actions as unwarranted encroachment on our private lives. We may indeed doubt the security of online participation in social networks or otherwise be fully apprised of the risks inherent in such activity, and decide to participate despite such risks. Indeed, Gefen et al. (2003) report that e-vendor customers' estimations of trust, usefulness, and ease of use have been shown to change over time. The authors found in their study that repeat customers were influenced in their purchase intentions both by trust and perceived usefulness in the e-vendor, whereas potential customers were only influenced by trust and not perceived usefulness. Gefen et al's (2003) findings are in alignment with our findings that trust is correlated with risk. Proficient users of social networks like Facebook have a better understanding of how to use the social network and are likely influenced both by trust 
and perceived usefulness, while still being wary of the risks inherent to sharing personal information online. Thus, it appears that users' risk tolerance might differ depending on their familiarity with the platform. However, this question requires further study.

\subsection{Contributions of the study}

This study is original in that it is the first to explore Facebook acceptance among CEGEP students. A better understanding of CEGEP students' technology acceptance can inform educators and technologists design of instructional applications and of development of information technologies targeting this population.

\subsection{Limitations and future directions}

Notwithstanding the strengths of the present study, there are some limitations that need to be addressed. First, the findings of the study are limited to the sample tested, which places restrictions on the generalizability of the results. There is a need to replicate the model in additional samples at different college levels, countries, and cultural contexts, in order to further test and evaluate the level of generalizability. Second, the research design employed in the study introduces some inherent limitations such as the issues associated with use of self-reported data. Further the cross-sectional design does not allow for causal interpretations, rather our findings are limited to general relatedness; this can be ameliorated in the future with longitudinal research. Finally, there are other constructs that could be related to the acceptance process, which future efforts could augment the model with additional salient constructs.

We did not test for the moderating influences of demographic factors such as age and gender; we leave such extensions to future research. A particularity of the study was the focus on Facebook as a platform but Facebook is now a rather ubiquitous part of everyday life. Therefore, generalizations to other populations and to other social networking sites are not advised. It would be interesting to apply the model for understanding acceptance and use of other social networking platforms among collegeage student populations as well.

\subsection{Conclusion}

The present study investigated the antecedents of Facebook use among CEGEP students. Using a PLS modeling approach, the hypothesized model was shown to be a good fit with our sample data. Our findings support the usefulness of TAM as a framework for investigating technology acceptance among college-age student populations.

\section{References}

Agarwal, R., Sambamurthy, V., \& Stair, R. (2000). Research report: The evolving relationship between general and specific computer self-efficacy-An empirical assessment. Information Systems Research, 11(4), 418-430. http://dx.doi.org/10.1287/isre.11.4.418.11876

Ajzen, I. (1991). The theory of planned behavior. Organizational Behavior and Human Decision Processes, 50(2), 179-211.

Bandura, A. (1995). Exercise of personal and collective efficacy in changing societies. In A. Bandura (Ed.), Self-efficacy in changing societies (pp. 1-45). New York: 
Cambridge University Press.

Burton-Jones, A., \& Hubona, G. S. (2006). The mediation of external variables in the technology acceptance model. Information \& Management, 43(6), 706-717. http://doi.org/10.1016/j.im.2006.03.007

Chin, W. W. (1998). The partial least squares approach for structural equation modeling. In G. A. Marcoulides (Ed.), Modern Methods for Business Research (pp. 295-336). Mahwah, NJ: Erlbaum.

Compeau, D. R., \& Higgins, C. A. (1995). Computer self-efficacy: Development of a measure and initial test. MIS Quarterly, 19(2), 189-211. http://dx.doi.org/10.2307/249688

Davis, F. D. (1989). Perceived usefulness, perceived ease of use, and user acceptance of information technology. MIS Quarterly, 13(3), 319-340.

Davis, F. D., Bagozzi, R. P., \& Warshaw, P. R. (1989). User acceptance of computer technology: A comparison of two theoretical models. Management Science, 35(8), 982-1003. http://dx.doi.org/10.1287/mnsc.35.8.982

Davis, F. D., Bagozzi, R. P., \& Warshaw, P. R. (1992). Extrinsic and intrinsic motivation to use computers in the workplace. Journal of Applied Social Psychology, 22(14), 1111-1132. http://dx.doi.org/10.1111/j.1559-1816.1992.tb00945.x

Doleck, T., Bazelais. P., \& Lemay, D. J. (2016). Examining the antecedents of social networking sites use among CEGEP students. Education and Information Technologies. doi: 10.1007/s10639-016-9535-4

Finstad, K. (2010). Response interpolation and scale sensitivity: Evidence against 5-point scales. Journal of Usability Studies, 5(3), 104-110.

Fishbein, M., \& Ajzen, I. (1975). Belief, attitude, intention, and behavior: An introduction to theory and research. Reading, MA: Addison-Wesley.

Fornell, C., \& Larcker, D. F. (1981). Evaluating structural equation models with unobservable variables and measurement error. Journal of Marketing Research, 18(1), 39-50.

Gefen, D. (2002). Customer loyalty in e-commerce. Journal of Association for Information Systems, 3, 27-51.

Gefen, D. (2003). TAM of just plain habit: A look at experienced online shoppers. Journal of Organizational and End User Computing, 15(3), 1-13.

Gefen, D., Karahanna, E., \& Straub, D. W. (2003). Inexperience and experience with online stores: The importance of tam and trust. IEEE Transactions On Engineering Management, 50(3), 307-321. http://dx.doi.org/10.1109/tem.2003.817277

Gefen, D., Straub, D. W., \& Boudreau, M. C. (2000). Structural equation modeling and regression: Guidelines for research practice. Communications of the Association for Information System, 4: 7.

Hair, J. F., Ringle, C. M., \& Sarstedt, M. (2011). PLS-SEM: Indeed a silver bullet. Journal of Marketing Theory and Practice, 19(2), 139-152. http://dx.doi.org/10.2753/mtp1069-6679190202

Henseler, J., Ringle, C. M., \& Sarstedt, M. (2015). A new criterion for assessing discriminant validity in variance-based structural equation modeling. Journal of the Academy of Marketing Science, 43(1), 115-135.

Holmström, S. (2007). Niklas Luhmann: Contingency, risk, trust and reflection. Public Relations Review, 33(3), 255-262. http://doi.org/10.1016/j.pubrev.2007.05.003

Hulland, J. (1999). Use of partial least squares (PLS) in strategic management research: A review of four recent studies. Strategic Management Journal, 20(2), 195-204.

Jamieson, S. (2004). Likert scales: How to (ab)use them. Medical Education, 38(12), 1217-1218. http://dx.doi.org/10.1111/j.1365-2929.2004.02012.x

Jarvenpaa, S. L., Tractinsky, N., \& Vitale, M. (2000). Consumer trust in an internet store. 
Information Technology and Management, 1, 45-71.

King, W. R., \& He, J. (2006). A meta-analysis of the technology acceptance model. Information \& Management, 43(6), 740-755. http://doi.org/10.1016/j.im.2006.05.003

Lai, H. M., \& Chen, C. P. (2011). Factors influencing secondary school teachers' adoption of teaching blogs. Computers \& Education, 56(4), 948-960.

Lampe, C., Wohn, D. Y., Vitak, J., Ellison, N. B., \& Wash, R. (2011). Student use of Facebook for organizing collaborative classroom activities. International Journal of Computer-Supported Collaborative Learning, 6(3), 329-347. http://dx.doi.org/10.1007/s11412-011-9115-y

Legris, P., Ingham, J., \& Collerette, P. (2003). Why do people use information technology? A critical review of the technology acceptance model. Information \& Management, 40(3), 191-204. http://dx.doi.org/10.1016/s0378-7206(01)00143-4

Libaque-Saenz, C. F., Wong, S. F., Chang, Y., Ha, Y. W., \& Park, M.-C. (2014). Understanding antecedents to perceived information risks: An empirical study of the Korean telecommunications market. Information Development, 32(1), 91-106. http://doi.org/10.1177/0266666913516884

Lok, C. K. (2015). Adoption of smart card-based e-payment system for retailing in Hong Kong using an extended technology acceptance model. In M. Quaddus \& A. G. Woodside (Eds.), E-services Adoption: Processes by Firms in Developing Nations Advances in Business Marketing and Purchasing (pp. 255-466). Emerald Group.

Mayer, R. C., Davis, J. H., \& Schoorman, F. D. (1995). An integrative model of organizational trust. Academy of Management Review, 20(3), 709-734. http://dx.doi.org/10.5465/amr.1995.9508080335

MacCallum, F. (2011). Understanding peer influence in children and adolescents. Child and Adolescent Mental Health, 16(3), 174-175. http://dx.doi.org/10.1111/j.14753588.2011.00617_10.x

McCoy, S., Everard, A., \& Jones, B. M. (2005). An examination of the technology acceptance model in Uruguay and the US: A focus on culture. Journal of Global Information Technology Management, 8(2), 27-45.

McFarland, D. J., \& Hamilton, D. (2006). Adding contextual specificity to the technology acceptance model. Computers in Human Behavior, 22(3), 427-447. http://doi.org/10.1016/j.chb.2004.09.009

Moore, G. C., \& Benbasat, I. (1991). Development of an instrument to measure the perceptions of adopting an information technology innovation. Information Systems Research, 2(3), 192-222. http://dx.doi.org/10.1287/isre.2.3.192

Neufeld, G., \& Maté, G. (2006). Hold on to your kids: Why parents need to matter more than peers. New York: Ballantine Books.

Newsroom. (2016). Company Info | Facebook Newsroom. Retrieved from http://newsroom.fb.com/company-info/

Pavlou, P. A. (2003). Consumer acceptance of electronic commerce: Integrating trust and risk with the technology acceptance model. International Journal of Electronic Commerce, 7(3), 101-134.

Ringle, C. M., Wende, S., \& Becker, J. M. (2015). SmartPLS 3. Bönningstedt: SmartPLS.

Rogers, E. M. (2003). Diffusion of innovations (5th edition). New York: The Free Press.

Ryan, A. M. (2000). Peer groups as a context for the socialization of adolescents' motivation, engagement, and achievement in school. Educational Psychologist, 35(2), 101-111. http://dx.doi.org/10.1207/s15326985ep3502_4

Schepers, J., \& Wetzels, M. (2007). A meta-analysis of the technology acceptance model: Investigating subjective norm and moderation effects. Information \& Management, 44(1), 90-103. http://doi.org/10.1016/j.im.2006.10.007

Straub, D., Keil, M., \& Brenner, W. (1997). Testing the technology acceptance model across cultures: A three country study. Information \& Management, 33(1), 1-11. 
Sun, H., \& Zhang, P. (2006). The role of moderating factors in user technology acceptance. International Journal of Human Computer Studies, 64(2), 53-78. http://doi.org/10.1016/j.ijhcs.2005.04.013

Taylor, S., \& Todd, P. A. (1995). Understanding information technology usage: A test of competing models. Information Systems Research, 6(2), 144-176.

Teo, T. (2009). Modelling technology acceptance in education: A study of pre-service teachers. Computers \& Education, 52(2), 302-312. http://dx.doi.org/10.1016/j.compedu.2008.08.006

Teo, T., \& Fan, X. (2013). Coefficient alpha and beyond: Issues and alternatives for educational research. Asia-Pacific Education Researcher, 22(2), 209-213. http://dx.doi.org/10.1007/s40299-013-0075-z

Teo, T. S. H., Lim, V. K. G., \& Lai, R. Y. C. (1999). Intrinsic and extrinsic motivation in Internet usage. Omega, 27(1), 25-37. http://dx.doi.org/10.1016/s03050483(98)00028-0

Thompson, R. L., Higgins, C. A., \& Howell, J. M. (1991). Personal computing: Toward a conceptual model of utilization. MIS Quarterly, 15(1), 125-143. http://dx.doi.org/10.2307/249443

Triandis, H. C. (1971). Attitude and attitude change. John Wiley \& Sons, New York.

Turkle, S. (2011). Alone together: Why we expect more from technology and less from each other. New York: Basic Books.

Vanderstraeten, R. (2002). Parsons, Luhmann and the theorem of double contingency. $\begin{array}{llll}\text { Journal of Classical } & \text { Sociology, } & \text { 77-92. }\end{array}$ http://doi.org/10.1177/1468795X02002001684

Venkatesh, V. (2000). Determinants of perceived ease of use: Integrating control, intrinsic motivation, and emotion into the technology acceptance model. Information Systems Research, 11(4), 342-365. http://dx.doi.org/10.1287/isre.11.4.342.11872

Venkatesh, V., \& Davis, F. D. (1996). A model of the antecedents of perceived ease of use: Development and test. Decision Sciences, 27(3), 451-481.

Venkatesh, V., \& Davis, F. D. (2000). A theoretical extension of the technology acceptance model: Four longitudinal field studies. Management Science, 46(2), 186204.

Venkatesh, V., Morris, M. G., Davis, G. B., \& Davis, F. D. (2003). User acceptance of information technology: Toward a unified view. MIS Quarterly, 27(3), 425-478.

Wold, H. (1982). Soft modeling: The basic design and some extensions. In K. G. Jöreskog \& H. Wold (Eds.), Systems Under Indirect Observation, Part II. Amsterdam: North Holland Press.

Yi, M. Y., Jackson, J. D., Park, J. S., \& Probst, J. C. (2006). Understanding information technology acceptance by individual professionals: Toward an integrative view. Information \& Management, 43(3), 350-363. http://dx.doi.org/10.1016/j.im.2005.08.006

Yousafzai, S. Y., Foxall, G. R., \& Pallister, J. G. (2010). Explaining internet banking behavior: Theory of reasoned action, theory of planned behavior, or technology acceptance model? Journal of Applied Social Psychology, 40(5), 1172-1202. http://dx.doi.org/10.1111/j.1559-1816.2010.00615.x 